Bu makaleye atıfta bulunmak için/To cite this article:

DİLEK, Ö. (2021). Doğalgaz Kullanım Tercihinde Etkili Olan Sosyo-Ekonomik Faktörlerin Analizi: Rize Örneği. Atatürk Üniversitesi Sosyal Bilimler Enstitüsü Dergisi, 25 (3), 951-967.

\title{
Doğalgaz Kullanım Tercihinde Etkili Olan Sosyo-Ekonomik Faktörlerin Analizi: Rize Örneği (*)
}

Önder DiLEK ${ }^{(* *)}$

Öz: Insanoğlunun gida ve barınma gibi temel ihtiyaçlarından sonra enerji ihtiyacının ilk sıralarda yer aldığı söylenebilir. Bu ihtiyacın karşılanmasında hem ekonomik hem de çevre dostu enerji kaynaklarının üretimi ve tüketimi önem arz etmektedir. Bu çalışma, Rize il merkezinde ikamet eden hane halklarının doğalgaz kullanımını etkileyen sosyoekonomik faktörlerin belirlenmesi amacıyla yapılmıştır. Uygulamada kullanılacak verilerin temini için gerekli olan anketlerin toplanması Covid-19 pandemisi nedeniyle online olarak gerçekleştirilmiştir. Anketlerden elde edilen elde edilen veriler ile logit model tahmin edilmiştir. Tahmin sonuçlarına göre; eşin çalışması, ailede yedi yaşından küçük çocuğun olması, ailedeki birey sayısı, aylık ortalama gelir, meslek, konut mülkiyeti, ısı yalıtımı ve aylık ortalama elektrik faturasının doğal gaz kullanımı etkilediği tespit edilmiştir. Ayrıca ikamet edilen evin/mahallenin doğal gaz alt yapısının olmaması, sistemin ilk abonelik/kurulum maliyetlerinin yüksekliği, doğal gazın pahalı olduğunun düşünülmesi ve ısınamama endişesi doğal gazı tercih etmeme nedenleri olarak tespit edilmiştir.

Anahtar Kelimeler: Doğalgaz, tüketici tercihi, Logit model, Rize

\section{Analysis of Socio-Economic Factors Affecting Natural Gas Usage Preference: Case of Rize}

\begin{abstract}
It can be said that after the basic needs of human beings such as food and shelter, the energy need ranks first. The production and consumption of both economical and environmentally friendly energy resources are important in meeting this need. This study was carried out to determine the socioeconomic factors affecting the natural gas use of households residing in the city center of Rize. Due to the Covid-19 pandemic, the surveys required to obtain data to be used in the application were collected online. The logit model has been estimated with the data obtained from the surveys. According to the estimation results; It has been determined that the work of the spouse, the presence of children under the age of seven in the family, the number of members in the family, the average monthly income, occupation, housing ownership, thermal insulation and the average monthly electricity bill affect the use of natural gas. In addition, the lack of natural gas infrastructure of the residence / neighborhood, the high initial subscription/ installation costs of the system, the thought that natural gas is expensive, and the anxiety of not being able to heat were identified as the reasons for not choosing natural gas.
\end{abstract}

Keywords: Natural Gas, consumer preferences, Logit model, Rize

\footnotetext{
*) Bilgi edinme aşamasındaki desteklerinden dolayı Rize Belediyesi ve Aksa Karadeniz Doğal Gaz Dağıtım A.Ş.' ye teşekkürlerimi sunarım.

$\left.{ }^{* *}\right)$ Dr. Öğr. Üyesi, Recep Tayyip Erdoğan Üniversitesi Fındıklı Uygulamalı Bilimler Yüksekokulu, Finans ve Bankacılık Bölümü (e-posta:onder.dilek@erdogan.edu.tr) @i ORCID ID. https://orcid.org/0000-0001-6659-4962

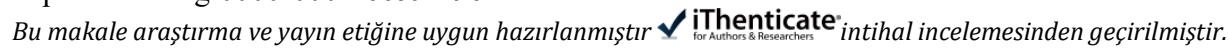


Makale Geliş Tarihi: 28.05.2021

Makale Kabul Tarihi: 20.09.2021

DOI: $10.53487 /$ ataunisosbil.944448

\section{Giriş}

Enerji kaynaklarının üretimi, tüketimi ve dağıtımı aşamaları küresel ısınma, iklim değişiklikleri gibi olumsuzluklara yol açabilmektedir. Fosil yakıtlarla kıyaslandığında doğal gazın çevre dostu ve temiz olması büyük şirketlerin dışsal maliyetlerinin azalmasına katkı sağlamaktadır (Umutlu ve Bayraç, 2020: 218). Diğer taraftan yüksek yanma verimi, depolanabilir olması, is gibi atık madde bırakmaması ve fiyat avantajlarından dolayı gerek konutlarda ısınma amaçlı gerekse sanayide üretim amaçlı kullanılmaktadır (Kaynar vd., 2011: 463). Bu geniş kullanımına rağmen üretimin büyük çoğunluğu beli başlı ülkelerce gerçekleştirilmektedir. Doğalgaz rezervleri bakımından en zengin beş ülke Rusya (39 trilyon $\left.\mathrm{m}^{3}\right)$, İran $\left(32\right.$ trilyon $\left.\mathrm{m}^{3}\right)$, Katar $\left(25\right.$ trilyon $\left.\mathrm{m}^{3}\right)$, Türkmenistan $\left(20\right.$ trilyon $\left.\mathrm{m}^{3}\right)$ ve ABD $\left(12\right.$ trilyon $\mathrm{m}^{3}$ ) olarak siralanmaktadır (Türkiye Petrolleri Anonim Ortaklığı, 2021).

Türkiye ilk doğalgaz anlaşmasını 1984 yılında SSCB ile gerçekleştirmiş (Gülcü ve Hatırlı, 2012: 84) ve ilk kullanım 1985 yılında başlamıştır (Koyuncu ve Bakırtaş, 2005: 29). Doğal gazın konutlarda ısınma amaçlı kullanımı ise ilk kez 1988 yılında Ankara'da başlamış, devam eden yıllarda İstanbul, Bursa, Eskişehir, Kocaeli gibi büyükşehirlerde yaygınlaşmıştır (Sarak ve Satman, 2003: 929). Artan kullanım zamanla doğalgaz ithalatının da yükselmesine neden olmuştur. Grafik 1'de 2009-2019 yılları arasındaki doğalgaz ithalat miktarları gösterilmektedir.

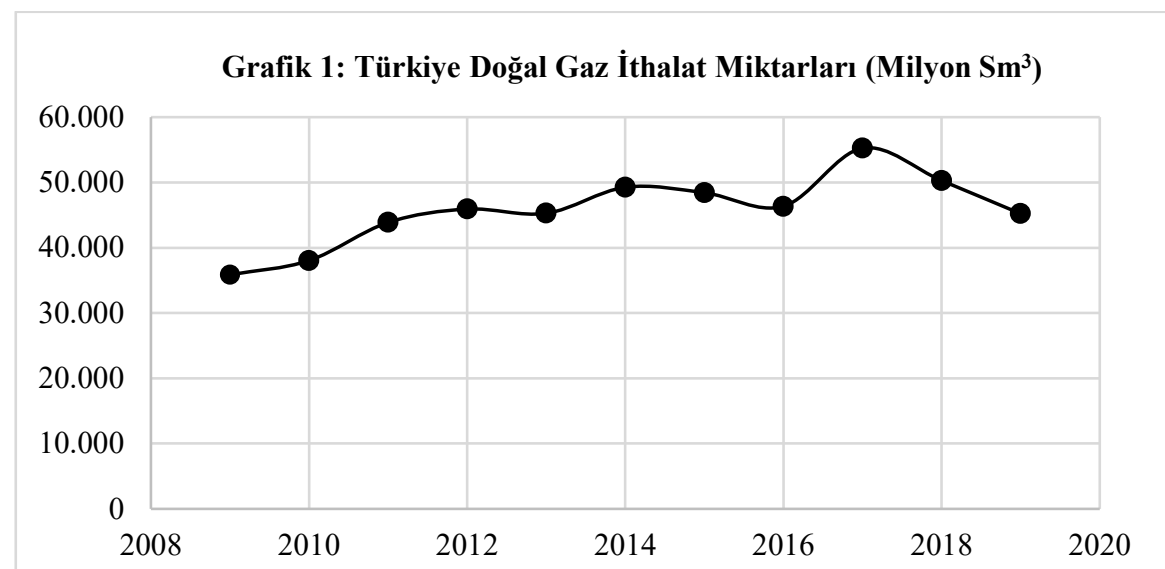

Kaynak: T.C. Enerji Piyasası Düzenleme Kurumu, Strateji Geliştirme Dairesi Başkanlığı, Doğal Gaz Piyasası, 2019 Yılı Sektör Raporu, S.8'deki verilerden elde edilmiştir. 
Türkiye 2019 yılında, 45.211,47 milyon $\mathrm{Sm}^{3}$ doğal gaz ithal etmiş, bu ithalatın \%33,6's1 Rusya, \%21,2'si Azerbaycan, \%17,1'i İran ve kalan kısmı ise Cezayir, Katar, Nijerya ve ABD'den gerçekleştirilmiştir (Türkiye Petrolleri Anonim Ortaklığı, 2021). Aynı yıl tüketim miktarı 45.285.498.424,37 $\mathrm{Sm}^{3}$ olarak gerçekleşmiş ve bu tüketimin \%32'si konutlarda, \%28'i sanayide, \%25'i ise elektrik santrallerinde kullanılmıştır. Ulusal doğal gaz tüketimi içinde Rize ilinin tüketim miktarı ise 93,224 milyon $\mathrm{Sm}^{3}$ 'tür (Enerji Piyasası Düzenleme Kurumu, 2021). Rize il merkezinde doğal gaz hizmeti 2007 yılında 4 abone ile başlamış, Nisan 2021 tarihi itibariyle 45.444 doğalgaz aboneye ulaşmıştır. ${ }^{\dagger}$

Bu çalışmanın amacı, Rize il merkezinde ikamet eden hanehalklarının doğal gaz kullanım tercihlerini etkileyen sosyo-ekonomik faktörlerin analiz edilmesidir. Çalışma beş bölümden oluşmaktadır. Giriş bölümünün ardından ikinci bölümde Hanehalkı doğalgaz tüketimi ve ilgili literatüre değinilmiştir. Üçüncü bölümde veri seti ve yöntem ele alınmıştır. Dördüncü bölümde bulgular ve analiz, beşinci bölümde ise çalışmanın sonuçlarına değinilmiştir.

\section{Hanehalkı Doğalgaz Tüketimi ve Literatür}

Hanehalkının kullandığı enerji türü tercihinde davranışları değerlendirmek birçok farklı alanlarda araştırmacıların ilgi odağı olmuştur. Bu çalışmalardan enerji ve doğal gaz tüketiminde etkili olan faktörlere yönelik çarpıcı sonuçlar elde edilmiştir. Hanedeki çocuk sayısının ve çocukların yaşlarının (Fritzche, 1981), hanede yaşayan fert sayısının (Poortinga vd., 2004; Çalmaşur ve Tuna, 2020) ve aile reisinin yaşının (Pachauri, 2004; Özcan vd., 2013) enerji tüketimini etkilediği, yaşlıların yaşadığı hane halklarının diğer hanelere göre fazla doğal gaz tükettiği (Liao ve Chang, 2002; Brounen vd., 2012), gelir seviyesi arttıkça doğalgaz kullanımının arttığı (Tarı, 2000; Gülcü ve Hatırlı, 2012; Özcan vd., 2013; Çalmaşur ve Tuna, 2020), ikamet edilen konutun bakımlı ve izolasyonlu olmasının doğal gaz tüketimini azalttığı (Verhallen ve Van Raaij; 1981; Brounen vd., 2012), bina yaşı ve büyüklüğü arttıkça doğalgaz kullanımın azaldığı (Gülcü ve Hatırl, 2012), konut büyüklüğünün doğal gaz tüketim maliyetlerini yükselttiği (Selçuk ve Pasinlioğlu, 2020), ikamet edilen konuta sahip olmayla doğalgaz kullanımı arasında pozitif yönlü bir ilişkinin olduğu (Oktay vd., 2008; Gülcü ve Hatırl1, 2012), konutun müstakil ya da apartman dairesi olmasının doğal gaz talebini önemli ölçüde etkilediği (Özçomak vd., 2006) yapılan çalışmalarda ortaya koyulmuştur.

Bu çalışmada, literatürdeki çalışmalardan yola çıkarak, demografik faktörler, ikamet edilen konuta ait özellikler ve ekonomik faktörler ile doğal gaz kullanımı arasındaki ilişki analiz edilmeye çalışılmıştır. Diğer taraftan enerji/doğal gaz tercih ve kullanımına yönelik yapılmış bazı ulusal ve uluslararası çalışmalar Tablo 1'de gösterilmiştir.

* 06.04.2021 Tarih, E-61702197-604.02-234 sayılı bilgi edinme dilekçe ile Aksa Karadeniz Doğal Gaz Dağıtım A.Ş'den elde edilmiştir. 
Tablo 1: Literatür Taraması

\begin{tabular}{|c|c|c|}
\hline Yazar & Ülke/Analiz & Sonuçlar \\
\hline $\begin{array}{l}\text { Fritzche } \\
(1981)\end{array}$ & $\begin{array}{c}\text { ABD, } \\
\text { Tüketici } \\
\text { Harcama } \\
\text { Anketleri }\end{array}$ & $\begin{array}{l}\text { Çocuk yetiştirme yılları boyunca enerji tüketiminin yükseldiği, en } \\
\text { küçük çocuğun altı yaşını doldurması ve çocukların büyüyüp evden } \\
\text { ayrılması halinde ise tüketimin azaldığı tespit edilmiştir. }\end{array}$ \\
\hline $\begin{array}{l}\text { Verhallen ve } \\
\text { Raaij (1981) }\end{array}$ & $\begin{array}{l}\text { Hollanda, } \\
\text { Hane halk1 } \\
\text { anketleri }\end{array}$ & $\begin{array}{l}\text { Konut özellikleri, özel durumlar ve demografik özelliklerin enerji } \\
\text { kullanım varyansının \%58'ini açıkladığını ve bunun \%24'ü evin } \\
\text { özellikleri, \%26'sı Hanehalkı davranışı, \%11'i özel durumlar } \\
\text { tarafından açıklandığı tespit edilmiştir. Ayrıca ev yalıtımının enerji } \\
\text { kullanımı üzerinde olumlu etkisi olduğu sonucuna ulaşılmıştır }\end{array}$ \\
\hline Tarı (2000) & $\begin{array}{l}\text { Türkiye } \\
\text { Anket, yatay } \\
\text { kesit verileri, } \\
\text { Logit model }\end{array}$ & $\begin{array}{l}\text { İkamet edilen konutun sobalı/kaloriferli olması ve gelir düzeyi doğal } \\
\text { gazı tercihini olumlu yönde etkilediği sonuca ulaşılmıştır }\end{array}$ \\
\hline $\begin{array}{l}\text { Pachauri } \\
(2004)\end{array}$ & $\begin{array}{l}\text { Hindistan, } \\
\text { Hanehalk1 anket } \\
\text { verileri, } \\
\text { OLS } \\
\end{array}$ & $\begin{array}{l}\text { Hanehalkı konutunun büyüklüğü ve hanehalkı reisinin yaşı ile enerji } \\
\text { ihtiyacı doğru orantılı, hanedeki birey sayısı ve aile reisinin } \\
\text { okuryazarlığı arasında enerji ihtiyacı negatif ilişkili olduğu tespit } \\
\text { edilmiştir. }\end{array}$ \\
\hline $\begin{array}{l}\text { Özçomak vd. } \\
\quad(2006)\end{array}$ & $\begin{array}{l}\text { Türkiye, } \\
\text { Anket, yatay } \\
\text { kesit verileri } \\
\text { Logit Model }\end{array}$ & $\begin{array}{l}\text { Y1llık toplam ısınma maliyeti, hava kirliği düzeyi, ikamet edilen } \\
\text { konutun apartman dairesi veya müstakil olma durumu ile } \\
\text { hanehalkının doğal gaz hakkındaki bilgi düzeyinin doğal gaz talebi } \\
\text { üzerinde önemli bir etkiye sahip olduğu sonucuna ulaşılmıştır. }\end{array}$ \\
\hline $\begin{array}{l}\text { Gonzalez vd. } \\
\quad(2007)\end{array}$ & $\begin{array}{l}\text { Arjantin } \\
\text { Anket, yatay } \\
\text { kesit verileri }\end{array}$ & $\begin{array}{l}\text { Anket uygulanan bölgede (Patagonya) yaşayan hanehalklarının } \\
\text { doğal gaz tüketim miktarlarının Avrupa ülkelerine göre çok yüksek } \\
\text { olduğu ve bunun binalarının inşaat yapısı ile ısıtma cihazlarının } \\
\text { kullanımından kaynaklandığı tespit edilmiştir }\end{array}$ \\
\hline $\begin{array}{l}\text { Oktay vd. } \\
(2008)\end{array}$ & $\begin{array}{l}\text { Türkiye, } \\
\text { Anket, yatay } \\
\text { kesit verileri, } \\
\text { Logit Model }\end{array}$ & $\begin{array}{l}\text { Doğal gazdan önce kullanılan tüp adeti, doğal gazdan önce } \\
\text { kullanılan ısınma sistemi, konut sahibi olma, doğal gazın kullanım } \\
\text { amacı, doğal gaz kullanım süresinin doğal gaz sistemi tercihinde } \\
\text { etkili olan faktörler olarak tespit edilmiştir. }\end{array}$ \\
\hline Işık (2010) & $\begin{array}{l}\text { Türkiye, } \\
\text { Birim Kök ve } \\
\text { ARDL }\end{array}$ & $\begin{array}{l}\text { Doğal gaz tüketimi ekonomik büyümeyi kısa dönemde pozitif, uzun } \\
\text { dönemde negatif yönde etkilediği tespit edilmiştir. }\end{array}$ \\
\hline $\begin{array}{l}\text { Gülcü ve Hatırlı } \\
\qquad(2012)\end{array}$ & $\begin{array}{l}\text { Türkiye, } \\
\text { Anket, yatay } \\
\text { kesit verileri, } \\
\text { Logit Model }\end{array}$ & $\begin{array}{l}\text { Gelir arttıkça doğalgaz kullanımının yaygınlaştığı, konutun } \\
\text { büyüklügü, binanın yaşı ve konutun niteliği ile doğalgaz kullanımını } \\
\text { arasında ise ters yönlü bir ilişki olduğu tespit edilmiştir. }\end{array}$ \\
\hline $\begin{array}{l}\text { Brounen vd. } \\
\quad(2012)\end{array}$ & $\begin{array}{c}\text { Hollanda, } \\
\text { Merkezi } \\
\text { İstatistik Bürosu } \\
\text { verileri } \\
\end{array}$ & $\begin{array}{l}\text { Bakımlı bir evde yaşayanlar ile yalıtımlı evlerde yaşayanların diğer } \\
\text { evlere nazaran doğalgaz tüketimlerinin } \% 12 \text { daha az olduğu ve } 30 \\
\text { yaşın üstündeki konutlarda ise gaz tüketiminin } \% 50 \text { daha yüksek } \\
\text { olduğu bulunmuştur. }\end{array}$ \\
\hline $\begin{array}{l}\text { Özcan vd. } \\
(2013)\end{array}$ & $\begin{array}{l}\text { Türkiye, } \\
\text { TÜIK, Hane } \\
\text { Halkı Bütçe } \\
\text { Anketleri }\end{array}$ & $\begin{array}{l}\text { Hanelerin aylık geliri ve yaşın enerji tercihi üzerinde önemli etkiye } \\
\text { sahip olduğu, ayrıca yaşlıların kullanım kolaylığ ve sağlık } \\
\text { nedenlerinin seçim üzerinde önemli etkiye sahip olduğu sonucuna } \\
\text { ulaşılmıştır. }\end{array}$ \\
\hline $\begin{array}{l}\text { Chang vd. } \\
\quad(2016)\end{array}$ & $\begin{array}{l}\text { G7 Ülkeleri, } \\
\text { Eşbütünleşme } \\
\text { ve Granger } \\
\text { Nedensellik }\end{array}$ & $\begin{array}{l}6 \text { ülkede doğal gaz tüketimi ile ekonomik büyüme arasında } \\
\text { nedensellik ilişki olduğu (İngiltere hariç) tespit edilmiştir. }\end{array}$ \\
\hline $\begin{array}{l}\text { Lebe veTatli } \\
\qquad(2017)\end{array}$ & $\begin{array}{l}\text { Türkiye, } \\
\text { Eşbütünleşme }\end{array}$ & $\begin{array}{l}\text { Doğal gaz tüketimi, sabit sermaye oluşumu ve istihdamın ekonomik } \\
\text { büyümeyi pozitif yönde etkilemekte ve uzun dönemde doğal gaz }\end{array}$ \\
\hline
\end{tabular}




\begin{tabular}{|c|c|l|}
\hline & $\begin{array}{c}\text { ve Granger } \\
\text { Nedensellik }\end{array}$ & $\begin{array}{l}\text { tüketimiyle ekonomik büyüme arasında nedensellik ilişkisi olduğu } \\
\text { sonucuna ulaşıllmıştır. }\end{array}$ \\
\hline $\begin{array}{c}\text { Türkiye, } \\
\text { Çalmaşur ve } \\
\text { Tuna (2020) }\end{array}$ & $\begin{array}{c}\text { Ailedeki birey sayısı, 1sınma gideri, ısı yalıtımı olmaması ile doğal } \\
\text { kesit verileri, } \\
\text { Logit Model }\end{array}$ & $\begin{array}{c}\text { gaz kullanma arasında negatif; konut büyüklüğü ve gelir ile doğal } \\
\text { gaz kullanma arasında pozitif bir ilişki olduğu tespit edilmiştir. }\end{array}$ \\
\hline
\end{tabular}

\section{Veri seti ve Yöntem}

$\mathrm{Bu}$ bölümde sırasıyla veri seti ve yöntem hakkında bilgilendirmeler verilecektir.

\section{A. Veri Seti}

Araştırmanın veri seti, Rize ilinde ikamet eden hanehalkı reislerine uygulanan anketlerden elde edilen yatay kesit verilerinden oluşmaktadır. TÜİK tarafından 2021 yılında açıklanan adrese dayalı nüfus kayıt sistemi sonuçlarına göre Rize il nüfusu 344.359 (Türkiye İstatistik Kurumu, 2021) ve Rize il merkezinde bulunan daire sayıs1 ise 60.446 'dır. $\$ \% 5$ önem düzeyinde, $\% 5$ hata payı ile anakütleyi temsil edecek minimum örnek büyüklügü ve dolayısıyla uygulanacak anket sayısı yaklaşık 384 olarak tespit edilmiştir. Anket oluşturulurken daha önce geçerliliği ve güvenirliliği test edilmiş ölçeklerden (Koyuncu ve Bakırbaş, 2005; Oktay vd., 2008; Brounen vd., 2012; Gülcü ve Hatırlı, 2012; Çalmaşur ve Tuna, 2020; Tuzun ve Çayın, 2021) faydalanılmıştır.

Anket uygulama aşamasına geçilmeden önce Recep Tayyip Erdoğan Üniversitesi Sosyal ve Beşerî Bilimler Etik Kurulundan 13.04.2021 tarihinde (Toplantı K. Sayısı:2021/100) etik izni alınmıştır. Anketler 15.04.2021-30.04.2021 tarihleri arasında, Covid-19 pandemisinden kaynaklanan tedbir ve yasaklar göz önünde bulundurularak 403 kişiye online olarak uygulanmıştır. Elde edilen veriler SPSS paket programı yardımıyla analiz edilmiştir. Anket tasarımının uygunluğunu ve ifadelerin anlaşılırlığını test etmek için 42 kişilik bir grupla pilot çalışma yapılmıştır. Pilot test katılımcılarından gelen geri bildirimler neticesinde çevrimiçi anket formundaki ifadeler son halini almıştır. Toplam 45 sorudan oluşan anketin ilk bölümünde katılımcıların demografik özeliklerin tespitine yönelik sorular (10 soru), ikinci bölümünde ikamet edilen konut özellikleri ve yakıt maliyetine yönelik sorular (13 soru), son olarak üçüncü bölümde ise doğal gaz tercih etmem/etmeme nedenlerine yönelik beşli Likert ölçeği (1=Kesinlikle Katılmıyorum,... 5=Kesinlikle Katılıyorum) soruları (22 soru) yer almıştır.

Araştırmada kullanılan değişkenlerin Cronbach alfa değerleri "doğal gaz tercih etme nedenleri" için $\alpha=0,871$ ve doğal gaz tercih etmeme nedenleri" içinse $\alpha=0,820$ olarak bulunmuştur. Bu sonuçlar kabul edilebilir değer olan "0,70" değerinin çok üzerindedir ve ankette kullanılan ölçeklerin güvenilir olduğunu göstermektedir (Coşkun vd., 2015: 126). 2021 yılı Nisan ayı itibariyle Rize il merkezinde bulunan 60.446 yerleşim

\footnotetext{
* 15.04.2021 Tarih, E-61702197-604.02-254 say1lı bilgi edinme dilekçesi ile Rize Belediyesinden elde edilmiştir.
} 
biriminin 45.444’ü doğal gaz kullanmaktadır. ${ }^{\S}$ Anket uygulaması yapılırken \%75 olan kullanım oranı dikkate alınmaya çalışılmış ve çalışmada doğal gaz kullanım oranı \%78 olarak tespit edilmiştir.

\section{B. Logit model}

Sosyal bilimlerde anket yoluyla elde edilen veriler genelde kesikli değer alan kategorik veya sıralamalı ölçekle elde edildiği için logit model uygulanmasının avantajlı olacağı söylenebilmektedir (Çokluk, 2010: 1395). Model uygulanmadan önce iki veya daha fazla veri seti arasında anlamlı bir ilişkinin olup olmadığı Pearson Ki-Kare testi (Bryman ve Cramer, 1990: 123) ile aranabilmektedir. Bu çalışmada öncelikle Pearson Ki-Kare testi ile bağımlı ve bağımsız değişkenler arasında anlamlılık ilişkisi aranmış ve ardından aralarında anlamlı çıkan değişkenler ile logit model tahmin edilerek hanehalkı doğalgaz kullanma olasılıkları araştırılmıştır. Kategorik bağımlı değişkenin ikili olduğu durumlarda kullanılan modellerden biri olan (Şenel ve Alatlı, 2014: 36; Özer, 2004: 75) logit model,

$$
P_{i}=\frac{1}{1+e^{-I_{i}}}=\frac{1}{1+e^{-\left(\beta_{0}+\beta_{i} X_{i}\right)}}
$$

biçimindeki lojistik birikimli dağılım fonksiyondan (BDF) türetilmektedir. $\mathrm{I}_{\mathrm{i}},-\infty$ ile $+\infty$ arasında değer alırken, $\mathrm{P}_{i}$; 0-1 arasında değer alır ve $\mathrm{P}_{\mathrm{i}}$ ile $\mathrm{I}_{\mathrm{i}}$ arasında doğrusal olmayan bir ilişki bulunmaktadır. Burada P incelenen olayın gerçekleşme olasılığı, I iki sonuçlu bağımlı değişkendir. Bağımsız değişken $\mathrm{k}$ adet olduğunda,

$$
L_{i}=l_{n}\left(\frac{P_{i}}{1-P_{i}}\right)=\beta_{0}+\beta_{1} X_{1}+\beta_{2} X_{2}+\ldots \beta_{k} X_{k}+n_{i}
$$

olur. $\mathrm{Bu}$ çalışmada $\left(\frac{P_{i}}{1-P_{i}}\right)$ hanehalkı doğalgaz kullanma olasılığının doğalgaz kullanmama (diğer yakıt türlerini kullanma) olasılığına oranıdır. Olasılığın bağımsız değişkene göre değişme oranı hem $\beta$ 'ya hem de değişimin ölçüldüğü olasılığın düzeyine bağlıdır (Özer, 2004: 7). Aşağıda yer alan formül ile ifade edilir.

$$
\frac{d P_{i}}{d X_{i}}=P_{i}\left(1-P_{i}\right) \beta_{i} n_{i}
$$

Burada 3 numaralı formül bağımsız değişkenlerdeki bir değişimin hanehalkı doğalgaz kullanma olasılığı üzerinde meydana getireceği değişimi verir. Logit modelde sabit terim bağımsız değişkenler sıfır olduğunda hanehalkı doğalgaz kullanımı etmelerinin log-olasılık oranı değerini göstermekteyken, eğim katsayıları ise bağımsız değişkenlerdeki 1 birim değişmeye karşılık logitteki $\left(\mathrm{L}_{\mathrm{i}}\right)$ değişmeyi göstermektedir (Gujarati, 1995: 555).

\footnotetext{
* 06.04.2021 Tarih, E-61702197-604.02-234 say1lı bilgi edinme dilekçesi ile Aksa Karadeniz Doğal Gaz Dağıtım A.Ş'den elde edilmiştir.
} 
Bağımlı değişken; evet-hayır, başarılı-başarısız, kullanıyorum-kullanmıyorum gibi iki değer alıyorsa tercih/karar belirtir ve bu veriler " 0 " ya da "1" değerlerini alan kukla değişkenlerle nicel hale getirilir (Tatlı, 2013: 45). Çalışmamızda bağımlı değişken hanehalkının doğalgaz kullanmaması, "0"; hanehalkının doğalgaz kullanması ise "1" değerini alacaktır. Modelde yer alan değişkenler tablo 2'e gösterilmektedir. Tabloda görüldüğü ailedeki birey sayısı hariç diğer tüm değişkenler nitel değişken oldukları için 0 ve 1 değeri alan kukla değişkenler ile temsil edilmiştir.

Logit modelin açıklayıcılığı Cox\&Snell $\mathrm{R}^{2}$ ve Nagelkerke $\mathrm{R}^{2}$ değerlerine göre yorumlanabilmektedir. Nagelkerke $\mathrm{R}^{2}$ değeri Cox\&Snell $\mathrm{R}^{2}$ değerine nazaran daha yüksek çıkmaktadır. Bu değerlerin 1'e yaklaşması bağımsız değişkenlerin açıklayıcılığının yükseldiğini göstermektedir (Çokluk, 2010: 1386). Modelin uyumun iyiliği Hosmer and Lemeshow testi ile ölçülmekte ve böylece modelin bir bütün olarak iyi bir model olup olmadığı gözlemlenebilmektedir. Hosmer and Lemeshow testine ait sig değerinin 0,05 'den büyük olması $(\mathrm{p}>0.05)$ oluşturulan modelin uyumunun iyi (Hosmer and Lemeshow, 1980: 147-156) olduğunu göstermektedir.

Tablo 2: Modelde Yer Alan Değişkenler

\begin{tabular}{|c|c|}
\hline Bağımlı Değişken (DGZ) & DGZ, 1 = Doğalgaz kullanan, $0=$ Kullanmayan \\
\hline Bağımsız Değişkenler & Kukla Değişkenler \\
\hline Cinsiyet (CNS) & $\mathrm{CNS}=1$, Erkek; $=0$, Kadın \\
\hline Medeni Durum (MD) & MD = 1, Evli; = 0, Bekâr \\
\hline Eş Çalışma (EÇ) & $\mathrm{EÇ}=1$, Eş çalışıyorsa; = 0, Çalışmıyorsa \\
\hline Konut Niteliği (KN) & $\mathrm{KN}=1$, Müstakil; = 0, Apartman Dairesi \\
\hline Is1 Yalitımı (IY) & $\mathrm{IY}=1$, Is1 Yalıtımı Var; $=0$, Yok \\
\hline Konut Mülkiyeti (KM) & $\mathrm{KM}=1, \mathrm{Kira} ;=0$, Ev Sahibi \\
\hline 7 Yaşından Küçük Çocuk (YKÇ) & YKÇ $=1,7$ yaş küçük çocuk var; $=0$, yok \\
\hline $\begin{array}{l}\text { Meslek (MES) } \\
\text { Referans Grup = Isşsiz }\end{array}$ & $\begin{array}{l}\text { MES1 }=1, \text { Kamu Personeli; = 0, Değil } \\
\text { MES2 }=1, \text { Özel Sektör Çalışanı; = 0, Değil } \\
\text { MES3 }=1, \text { Serbest Meslek; = 0, Değil } \\
\text { MES4 }=1, \text { İşçi ise } ;=0 \text {, Değil } \\
\text { MES5 }=1, \text { Emekli ise } ;=0 \text {, Değil }\end{array}$ \\
\hline $\begin{array}{l}\text { Yaş (YAS) } \\
\text { Referans Grup }=48 \text { yaş ve üzeri }\end{array}$ & $\begin{array}{l}\text { YAS1 }=1, \text { Yaş } 18-27 \text { ise } ;=0, \text { Değil } \\
\text { YAS2 }=1, \text { Yaş1 } 28-37 \text { ise } ;=0, \text { Değil } \\
\text { YAS3 }=1, \text { Yaş1 38-47 ise } ;=0, \text { Değil }\end{array}$ \\
\hline $\begin{array}{l}\text { Gelir (GLR) } \\
\text { Referans Grup = 9001 TL ve üzeri }\end{array}$ & $\begin{array}{l}\text { GLR1 }=1,0-3000 \text { TL ise } ;=0, \text { Değil } \\
\text { GLR2 }=1 ; 3001-4500 \text { TL ise } ;=0 \text {, Değil } \\
\text { GLR3 }=1,4501-6000 \text { TL ise } ;=0, \text { Değil } \\
\text { GLR4 }=1,6001-7500 \text { TL ise }=0 \text {, Değil } \\
\text { GLR5 }=1,7501-9000 \text { TL ise } ;=0, \text { Değil }\end{array}$ \\
\hline
\end{tabular}




\begin{tabular}{|c|c|}
\hline $\begin{array}{l}\text { Elektrik Faturası }(\mathrm{EF}) \\
\text { Referans Grup }=351 \mathrm{TL} \text { ve üzeri }\end{array}$ & $\begin{array}{l}\mathrm{EF} 1=1,0-150 \mathrm{TL} \text { ise } ;=0, \text { Değil } \\
\mathrm{EF} 2=1,151-250 \mathrm{TL} \text { ise } ;=0, \text { Değil } \\
\mathrm{EF} 3=1,251-350 \mathrm{TL} \text { ise } ;=0, \text { Değil }\end{array}$ \\
\hline $\begin{array}{l}\text { Konut Büyüklüğü m² }(\mathrm{KB}) \\
\text { Referans Grup }=201 \mathrm{~m}^{2} \text { ve üzeri }\end{array}$ & $\begin{array}{l}\mathrm{KB} 1=1,101-150 \mathrm{~m}^{2} \text { aras1 } ;=0, \text { Değil } \\
\mathrm{KB} 2=1,151-200 \mathrm{~m}^{2} \text { aras1 } ;=0 \text {, Değil } \\
\mathrm{KB} 3=1,201 \mathrm{~m}^{2} \text { ve üstü; }=0 \text {, Değil }\end{array}$ \\
\hline Birey Say1sı( BS) & Sürekli Değişken \\
\hline
\end{tabular}

\section{Bulgular ve Analiz}

$\mathrm{Bu}$ kısımda temel bulgulara ait sonuçlar gösterilmektedir. İlk olarak tablo 3 'te hanehalkına ait demografik ve ekonomik göstergelere yer verilmektedir. Ardından tablo 4 'te ikamet edilen konuta ilişkin bilgiler, tablo 5 'te doğal gaz tercih etme nedenleri ve tablo 6'da doğal gaz tercih etmeme nedenleri gösterilmektedir. Temel bulguların ardından ise analiz sonuçlarına yer verilmektedir.

Tablo 3: Demografik ve Ekonomik Göstergeler

\begin{tabular}{c|c|c|c}
\hline \hline \multicolumn{2}{c|}{ Değissken } & Sayı & \% \\
\hline \hline \multirow{2}{*}{ Cinsiyet } & Erkek & 302 & 74,9 \\
\multirow{2}{*}{ Medeni Durum } & Kadın & 101 & 25,1 \\
\hline \multirow{2}{*}{ Eş Çalışma } & Evli & 335 & 83,1 \\
& Bekâr & 68 & 16,9 \\
\hline \multirow{3}{*}{ Yaş } & Evet & 130 & 32,3 \\
& Hayır & 205 & 50,9 \\
& Bekâr & 68 & 16,9 \\
\hline \multirow{3}{*}{ Birey Sayısı } & $18-27$ & 78 & 19,4 \\
& $28-37$ & 100 & 24,8 \\
& $38-47$ & 160 & 39,7 \\
& $48+$ & 65 & 16,1 \\
\hline \multirow{2}{*}{ 7 Yaşından Küçük Çocuk } & 1 & 13 & 3,2 \\
& 2 & 26 & 6,5 \\
& $3-4$ & 231 & 57,3 \\
\multirow{2}{*}{ Aile Büyüğü } & $5-6$ & 108 & 26,8 \\
& 7 & 25 & 6,2 \\
\hline & Yok & 258 & 64,0 \\
& Var & 145 & 36,0 \\
\hline & Yok & 293 & 72,7 \\
& Var & 110 & 27,3 \\
\hline
\end{tabular}




\begin{tabular}{c|c|r|r}
\hline \multirow{4}{*}{ Gelir } & 3000 TL'ye kadar & 117 & 29,0 \\
& $3001-4500 \mathrm{TL}$ & 110 & 27,3 \\
& $4501-6000 \mathrm{TL}$ & 60 & 14,9 \\
& $6001-7500 \mathrm{TL}$ & 40 & 9,9 \\
& $7501-9000 \mathrm{TL}$ & 31 & 7,7 \\
& $9001 \mathrm{TL}+$ & 45 & 11,2 \\
\hline \multirow{3}{*}{ Eğitim Durumu } & İlköğretim & 68 & 16,9 \\
& Lise & 125 & 31,0 \\
& Üniversite & 160 & 39,7 \\
& Lisansüstü & 50 & 12,4 \\
\hline \multirow{3}{*}{ Meslek } & Kamu Personeli & 104 & 25,8 \\
& Özel Sektör & 90 & 22,3 \\
& Esnaf & 77 & 19,1 \\
& İşçi & 76 & 18,9 \\
& Emekli & 36 & 8,9 \\
& İşsiz & 20 & 5,0 \\
\hline
\end{tabular}

Tablo 3'te görüldüğü üzere, katılımcıların \%74,9'u erkek, \%25,1'i ise kadındır. \%83,1'i evli, \%16,9'u ise bekârdır. En yüksek yaş grubu \%39,7 ile 38-47 yaş aralığı, en yüksek gelir grubu ise \%29 ile 3.000 TL'ye kadar olan gelir seviyesindekilerdir. Ailedeki birey sayısı en yüksek olan grup \%57,3 ile 3-4 kişi olanlardır. Aile reisinin \%39,7'si üniversite mezunu, \%25,8'i kamu personelidir.

Tablo 4: İkamet Edilen Konuta İlişkin Bilgiler

\begin{tabular}{c|c|r|c}
\hline \hline \multicolumn{2}{c|}{ Değisken } & Sayı & \% \\
\hline \hline \multirow{2}{*}{ Konut Niteliği } & Müstakil & 69 & 17,1 \\
& Apt. Dairesi & 334 & 82,9 \\
\hline \multirow{2}{*}{ Mülkiyet } & Kira & 143 & 35,5 \\
& Kendi Evi & 260 & 65,5 \\
\hline \multirow{2}{*}{ Isı Yalıtımı } & Evet & 241 & 59,8 \\
& Hayır & 162 & 40,2 \\
\hline \multirow{2}{*}{ Konut m ${ }^{2}$} & $100 \mathrm{~m} 2 \mathrm{kadar}$ & 61 & 15,1 \\
& $101-150 \mathrm{~m} 2$ & 279 & 69,2 \\
& $151-200 \mathrm{~m} 2$ & 38 & 9,4 \\
\multirow{2}{*}{ Isınma Sistemi } & $201 \mathrm{~m} 2+$ & 25 & 6,2 \\
& Doğal Gaz & 315 & 78,2 \\
& Diğer & 88 & 21,8 \\
\hline \multirow{2}{*}{ Sistem } & Kombi & 274 & 87,0 \\
& Merkezi Sistem & 41 & 13,0 \\
\hline
\end{tabular}




\begin{tabular}{c|c|c|c}
\hline & $200 \mathrm{TL}$ ve altı & 10 & 3,2 \\
Doğal Gaz Fatura (Kış & $201-300 \mathrm{TL}$ & 58 & 18,4 \\
Ayları Ortalama) & $301-400 \mathrm{TL}$ & 97 & 30,8 \\
& $401-500 \mathrm{TL}$ & 80 & 25,4 \\
& $501 \mathrm{TL}+$ & 70 & 22,2 \\
\hline \multirow{3}{*}{ Doğal Gaz Fatura } & $100 \mathrm{TL}$ ve altı & 17 & 5,4 \\
(12 Aylık Ort.) & $101-150 \mathrm{TL}$ & 49 & 15,36 \\
& $151-200 \mathrm{TL}$ & 79 & 25,1 \\
& $201-250 \mathrm{TL}$ & 83 & 26,3 \\
& $251-300 \mathrm{TL}$ & 45 & 14,3 \\
& $301 \mathrm{TL}+$ & 42 & 13,3 \\
\hline \multirow{3}{*}{ Aylık Elektrik Faturası } & $150 \mathrm{TL}$ ve altı & 110 & 27,3 \\
& $151-250 \mathrm{TL}$ & 196 & 48,6 \\
& $251-350 \mathrm{TL}$ & 55 & 13,6 \\
& $351 \mathrm{TL}+$ & 42 & 10,4 \\
\hline
\end{tabular}

Tablo 4'te görüldüğü üzere ikamet edilen konutun \%82,9'u apartman dairesi, \% 17,1'i müstakildir. Katılımsıların \%64,5'i kendi evinde, \%35,5'i ise kirada ikamet etmektedir. Konut büyüklüğü açısından incelendiğinde \%69,2'sinin 101-150 m² alana sahip konutlar olduğu, \%78,2'sinin ısınma sistemi olarak doğalgazı tercih etiği görülmektedir. En yüksek doğal gaz faturası ödeyen grubun kış aylarında \%30,8 ile 301400 TL, 12 aylık ortalamada ise \%26,3 ile 201-250 TL olduğu tespit edilmiştir.

Tablo 5. Doğal Gaz Tercih Nedenleri

\begin{tabular}{l|r|r|c}
\hline \hline Faktörler & Min. & Max. & Mean \\
\hline \hline Kullanımının rahat olması & 1,00 & 5,00 & 4,5238 \\
Isınmayı ve sıcak suyu aynı anda karşılaması & 1,00 & 5,00 & 4,4476 \\
İs ve kül gibi problemlerin olmaması & 1,00 & 5,00 & 4,4381 \\
Evin istenilen bölümlerin istenilen zamanda ısıtılma & 1,00 & 5,00 & 4,3937 \\
imkânı & 1,00 & 5,00 & 4,3705 \\
Çevreye daha az zarar vermesi & 1,00 & 5,00 & 4,2032 \\
Tedarik etmenin kolay olması & 1,00 & 5,00 & 4,1302 \\
Mutfak ve banyoda diğer yakıt türlerine göre daha & & & \\
ucuz olması & 1,00 & 5,00 & 4,0762 \\
Diğer yakıt türlerine göre daha güvenilir olması &
\end{tabular}


Genel olarak diğer yakıt türlerine göre daha ucuz olmas 1

Isınmada diğer yakıt türlerine göre daha ucuz olması

Sadece kullanıldığı kadar maliyeti katlanmak istenmesi

Apartmanın ortak kararı

Çevredeki tüketicilerin tavsiyesi

Altyapısını doğal gaz olan Lojmanda oturulması

\begin{tabular}{|l|l|l}
1,00 & 5,00 & 3,7302 \\
1,00 & 5,00 & 3,6825 \\
& & \\
1,00 & 5,00 & 3,6381 \\
1,00 & 5,00 & 3,4413 \\
1,00 & 5,00 & 3,3429 \\
1,00 & 5,00 & 3,1111
\end{tabular}

Tablo 5'te doğal gaz tercih etme nedenleri görülmektedir. Bu nedenlerden ilk 5'i şu şekilde sıralanmaktadır. En yüksek ortalama $(4,5238)$ ile ilk sırada "kullanımının rahat olması" gelmektedir. İkinci sırada $(4,4476)$ "isınmayı ve sıcak suyu aynı anda karşılaması", üçüncü sırada $(4,4381)$ "is ve kül gibi problemlerin olmaması”, dördüncü sırada $(4,3937)$ "evin istenilen bölümlerin istenilen zamanda 1sıtılma imkânı" ve beşinci sirada $(4,3705)$ ise "tedarik etmenin kolay olması" gelmektedir.

Tablo 6. Doğal Gaz Tercih Etmeme Nedenleri

\begin{tabular}{l|c|c|c}
\hline \hline Faktörler & Min. & Max. & Mean \\
\hline \hline İkamet edilen evin doğal gaz alt yapısının olmaması & 1,00 & 5,00 & 4,1591 \\
İkamet edilen mahallede doğal gaz alt yapısının olmaması & 1,00 & 5,00 & 4,1023 \\
Sistemin ilk abonelik/kurulum maliyetlerinin yüksekliği & 1,00 & 5,00 & 2,7500 \\
Doğal gazın pahalı olduğunun düşünülmesi & 1,00 & 5,00 & 2,7159 \\
Isınamama endişesi & 1,00 & 5,00 & 2,4773 \\
Apartman çoğunluğunun kullanmak istememesi & 1,00 & 5,00 & 2,3068 \\
Güvenilir olmadığının düşünülmesi & 1,00 & 5,00 & 2,2841 \\
Çevremdeki kullanıcıların memnuniyetsizliği & 1,00 & 5,00 & 2,1818
\end{tabular}

Tablo 6'da doğal gaz tercih etmeme nedenleri görülmektedir. İlk iki sıranın yüksek ortalamaya sahip olduğu diğer nedenlerin ise düşük ortalamaya sahip olduğu görülmektedir. İlk sırada 4,1591 ortalama ile "ikamet edilen evin doğal gaz alt yapısının olmaması" yer almaktadır. İkinci sırada $(4,1023)$ "ikamet edilen mahallede doğal gaz alt 
yapısının olmaması", üçüncü sırada (2,7500) “sistemin ilk abonelik/kurulum vb. maliyetlerinin yüksekliği”, dördüncü sırada $(2,7159)$ "doğal gazın pahalı olduğunun düşünülmesi" ve beşinci sırada $(2,4773)$ ise "isınamama endişesi”" gelmektedir.

Hanehalkı doğal gaz kullanımında etkili olacağı tahmin edilen değişkenler ile doğalgaz kullanımı arasındaki ilişkiler öncelikle Ki-kare testine tabi tutulmuştur. Tablo 2'de yer alan bağımsız değişkenlerden "eğitim durumu" ve "aile büyüğü sayısı" değişkenleri ile doğal gaz kullanımı arasında anlamlı bir ilişki bulunamadığı $(\mathrm{P}>0,05)$ için modelden dışlanmış, anlamlı çıkan ve modele dahil edilen diğer tüm değişkenler tablo 7'de gösterilmiştir.

Tablo 7: Kullanılan Yakıt Türü İle Değişkenler Arasındaki İlişki

\begin{tabular}{l|c|r|l|r|c}
\hline \hline Değişken & $\begin{array}{c}\text { Ki-Kare } \\
\text { Değeri }\end{array}$ & Prob. & Değişken & $\begin{array}{r}\text { Ki-Kare } \\
\text { Değeri }\end{array}$ & Prob. \\
\hline \hline Cinsiyet & 12,011 & 0,001 & 7 yaş ve altı çocuk & 11,834 & 0,003 \\
Yaş & 10,249 & 0,017 & Konut niteliği & 147,421 & 0,000 \\
Medeni durum & 8,680 & 0,003 & Konut Büyüklüğü & 23,658 & 0,000 \\
Eş çalışma & 8,732 & 0,013 & Konut mülkiyeti & 6,641 & 0,011 \\
Meslek & 25,267 & 0,000 & Is1 yalıtımı & 14,765 & 0,000 \\
Gelir & 36,617 & 0,000 & Elektrik faturası & 39,840 & 0,000 \\
Birey say1s1 & 41,712 & 0,000 & & &
\end{tabular}

Tablo 7'deki değişkenler ile logit model tahmin edilmiştir. Tahmin edilen ilk modelde cinsiyet, yaş, medeni durum, konut niteliği ve konut büyüklüğü değişkenleri belirlenen önem düzeyinde istatistiki açıdan anlamsız oldukları için $(\mathrm{p}>0,05)$ modelden dışlanmıştır. İstatistiki açıdan anlamlı olan değişkenlerle nihai model tahmin edilmiş ve sonuçlar Tablo 8'de gösterilmiştir.

Tablo 8: Logit Model Sonucu

\begin{tabular}{|c|c|c|c|c|c|c|c|c|}
\hline & \multirow{2}{*}{ B } & \multirow{2}{*}{ S.E. } & \multirow{2}{*}{ Wald } & \multirow{2}{*}{ df } & \multirow{2}{*}{$\mathbf{P}$} & \multirow{2}{*}{$\operatorname{Exp}(B)$} & \multicolumn{2}{|c|}{$95 \% \operatorname{EXP}(B)$} \\
\hline & & & & & & & Lower & Upper \\
\hline$\overline{\mathrm{C}}$ & 1,219 & 1,822 & ,448 & 1 & 2,053 & 3,385 & & \\
\hline GLR1 & $-2,056$ & 829 & 6,156 & 1 & 013 &, 128 &, 025 & 649 \\
\hline MES2 & 1,491 &, 820 & 3,305 & 1 &, 069 & ,225 &, 045 & 1,124 \\
\hline KM & 1,079 & ,397 & 7,400 & 1 & ,007 & 2,942 & 1,352 & 6,403 \\
\hline IY & ,938 & ,432 & 4,699 & 1 & ,030 & 2,554 & 1,094 & 5,960 \\
\hline BS &,- 605 &, 157 & 14,878 & 1 &, 000 &, 546 &, 401 & ,743 \\
\hline $\mathrm{EÇ}$ & 895 & ,474 & 3,559 & 1 & 059 & ,409 &, 161 & 1,035 \\
\hline YKÇ & 1,374 &, 751 & 3,347 & 1 & 067 & ,253 &, 058 & 1,103 \\
\hline EF1 & 1,737 & 659 & 6,942 & 1 &, 008 & 5,679 & 1,560 & 20,672 \\
\hline EF2 & 2,210 & 621 & 12,655 & 1 &, 000 & 9,120 & 2,698 & 30,825 \\
\hline
\end{tabular}




\begin{tabular}{ll|lr}
\hline Nagelkerke R & & \\
Cox \& Snell R & 0.561 & -2 Log likelihood & 240,210 \\
Model tahmin oran1 & 0,365 & Hosmer and Lemeshow (sig) P & 0,191 \\
\hline
\end{tabular}

Not: C, MES2, EÇ ve YKÇ \%1, diğerleri \%5 önem düzeyinde istatistiki bakımdan anlamlı

Tablo 8'de verilen logit model sonuçlarını incelediğinde katsayıların işaretleri negatif olan GLR1 ve BS değişkenleri ile doğal gaz kullanma arasında negatif yönlü bir ilişki olduğu diğer değiş̧kenlerle ise pozitif yönde bir ilişki olduğu ortaya görülmektedir. Aylık ortalama geliri 3000 TL ve altında olanların (GLR1) aylık ortalama geliri 9001 TL ve üzerinde olanlara göre doğal gaz kullanma olasılıklarının 0,128 kat daha az olduğu tespit edilmiştir. Ayrıca sürekli değişken olarak modelde yer alan ailedeki birey sayısının (BS) bir kişi artması durumunda doğal gaz kullanma olasıllı̆ının 0,546 kat daha az olacağı sonucuna ulaşılmışıır.

İkamet edilen konutta 1sı yalıtımı olanların (IY) 1S1 yalıtımı olmayanlara göre doğal gaz kullanma olasılı̆̆ının 2,554 kat, özel sektör çalışanlarının (MES2) işsizlere göre doğal gaz kullanma olasılığının 0,225 kat, kirada oturanların (KM) kendi evinde oturanlara göre doğal gaz kullanma olasılı̆ı̆ının 2,942 kat, eşi çalışanların (EÇ) eşi çalışmayanlara göre doğal gaz kullanma olasılı̆̆ının 0,409 kat, ailede yedi yaşından küçük çocuğu (YKÇ) olanların olmayanlara göre doğal gaz kullanma olasılıklarının 0,253 kat daha fazla olduğu tespit edilmiştir.

Aylık ortalama elektrik faturası $150 \mathrm{TL}$ ve altında olanların (EF1) aylık ortalama elektrik faturası $351 \mathrm{TL}$ ve üzerinde olanlara göre doğal gaz kullanma olasılı̆̆ının 5,679 kat ve son olarak aylık ortalama elektrik faturası 151-250 TL arasinda olanların (EF2) aylık ortalama elektrik faturası $351 \mathrm{TL}$ ve üzerinde olanlara göre doğal gaz kullanma olasılığının 9,120 kat daha fazla olduğu sonucuna ulaşılmıştır.

Nagelkerke $\mathrm{R}^{2}$ değerinin 0,561 olması bağımlı değişkendeki değişimin \%56,1'nin modelde yer alan bağımsız değişkenler tarafından açıklandığı göstermektedir. Hosmer and Lemeshow testine ait (sig) $p$ değerinin 0,191 olması ( $p>0.05$ ) ise oluşturulan modelin bir bütün olarak uyumunun iyi olduğunu göstermektedir.

\section{Sonuç}

Bir yandan değişen yaşam koşulları diğer yandan gelişen teknoloji enerjiye olan ihtiyacı her geçen gün artırmaktadır. Bu ihtiyacın karşılanmasında düşük maliyetlerin tercih edilmesi kadar önemli olan bir diğer faktör de çevreye verilen zararın mümkün olduğu kadar en aza indirgenebilmesidir. Alternatif yakıt (fosil) türlerine nazaran çevre dostu olarak anılan doğalgazın tercih edilmesinde etkili olan sosyoekonomik faktörlerin belirlenmesine yönelik birçok araştırma olmasına karşın Rize ölçeğinde bir çalışmanın olmaması bu çalışmanın motivasyon kaynaklarından biri olmuştur. Türkiye'de ilk doğalgaz kullanımı 1985 yılında başlamasına rağmen Rize'de ancak 2007 yılında kullanılmaya başlamış ve o günden bugüne kullanım oranı $\% 75$ seviyelerine ulaşmıştır.

Bu çalışma, Rize il merkezinde ikamet eden hanehalklarının doğal gaz kullanım tercihlerini etkileyen sosyo-ekonomik faktörlerin analiz edilmesi amaciyla gerçekleştirilmiştir. Covid-19 pandemisi nedeniyle hanehalkı reislerine online anket uygulanmış ve elde edilen verilerle logit model tahmin edilmiştir. Araştırmada 
kullanılan değişkenlerin Cronbach alfa değerleri "doğal gaz tercih etme nedenleri" için $\alpha=0,871$ ve doğal gaz tercih etmeme nedenleri" için $\alpha=0,820$ olarak bulunmuştur.

Literatürdeki çalışmalardan yola çıkarak doğalgaz kullanım tercihine etkisi olan "sosyoekonomik faktörler" ile "ikamet edilen konuta dair özelikler" uygulanan modelde bağımsız değişkenler olarak yer almıştır. Bu değişkenlerden cinsiyet, yaş, medeni durum, eğitim durumu, aile büyüğü (dede, nine) sayısı, konutun niteliği ve konutun büyüklüğü dışında kalan faktörlerin doğalgaz kullanım tercihi üzerinde etkili oldukları sonucuna ulaşıılmıştır.

Aylık ortalama geliri 3000 TL ve altında olanların 9001 TL ve üzerinde olanlara göre doğal gaz kullanma olasılıklarının daha az olduğu tespit edilmiş̧tir. Yaklaşık on yıl önce (Tarı, 2000; Gülcü ve Hatırlı, 2012; Özcan vd., 2013) yapılmış olan çalışmalarda benzer sonuçlar elde edilmiş olması gelir seviyesinin doğalgaz kullanım tercihini etkileyen önemli bir faktör olduğunun göstergesidir. Erzurum ölçeğinde yapılan çalışmaya (Çalmaşur ve Tuna, 2020) paralel bir sonuç olarak ailedeki birey sayısının bir kişi artması durumunda doğal gaz kullanma olasılı̆̆ının daha az olacağı tespit edilmiștir. İklim olarak birbirinden çok farklı iki il olmasına rağmen bu sonuç ailede yaşayan birey sayısının doğal gaz tercihine olan etkisinin önemini göstermektedir.

Yapılan bazı araştırmaların (Oktay vd., 2008; Gülcü ve Hatırlı, 2012) aksine kirada oturanların kendi evinde oturanlara göre doğalgaz kullanma olasılıklarının daha fazla oluğu görülmüştür. Özel sektör çalışanlarının işsizlere göre, eşi çalışanların eşi çalışmayanlara göre, ailede yedi yaşından küçük çocuğu olanların olmayanlara göre, aylık ortalama elektrik faturası düşük olanların elektrik faturası yüksek olanlara göre ve ikamet edilen konutta 1s1 yalıtımı olanların 1sı yalıtımı olmayanlara göre doğal gaz kullanma olasılıklarının daha fazla olduğu sonuçlarına ulaşılmıştır. Doğalgaz kullanım tercihi üzerinde etkisi olduğu düşünülen aile reisinin yaşı (Pachauri, 2004; Özcan vd., 2013), konutun büyüklüğ̈̈ (Gülcü ve Hatırlı, 2012) ve konutun müstakil ya da apartman dairesi olması (Özçomak vd., 2006) değişkenlerinin yapılan diğer çalışmaların aksine doğalgaz kullanım tercihi üzerinde herhangi bir etkisinin olmadığı sonucuna ulaşılmışır.

Doğal gaz kullanımının rahat olması, ısınmayı ve sıcak suyu aynı anda karşılaması, is, kül gibi problemlerin olmaması, evin istenilen bölümlerinin istenilen zamanda ssıtılma imkânın olması ve tedarik kolaylığı nedenleriyle tercih edildiği tespit edilmiştir. Diğer taraftan ikamet edilen evin/mahallenin doğal gaz alt yapısının olmaması, sistemin ilk abonelik/kurulum maliyetlerinin yüksekliği, doğal gazın pahalı olduğunun düşünülmesi ve isınamama endișesi doğal gazı tercih etmeme nedenleri olarak tespit edilmiştir. Özellikle ikamet edilen evin/mahallenin doğal gaz alt yapısının olmaması ve sistemin ilk abonelik/kurulum maliyetlerinin yüksekliği doğalgaz kullanımını tercih etmeme nedenleri arasında zirvede yer almaktadır. Bu hizmeti sağlayan firmaların altyapı çalışmalarına hız vermesi ve abonelik maliyetlerinde indirime gidilmesi veya alternatif ödeme kolaylıklarının sağlanmasının doğalgaz kullanım tercihini arttıracağı düşünülmektedir.

Araştırmanın Rize ili ile kısıtlı olması elde edilen sonuçların genele yayılmasına engel teşkil etmektedir. Ancak, il genelinde doğalgaz kullanmayan kesimin \%25 seviyelerinde olması göz önünde bulundurulduğunda çalışma sonuçları hizmet sağlayıcı 
firma ve kamu otoritesine ileriye dönük planlama yapılabilmesi açısından önemli veriler sağlamaktadır. Konuya ilgi duyan araştırmacıların ana kütleyi ulusal ölçekte genişletmesi geçerliliği yüksek bulgulara erişilmesine ve daha sağlıklı önerilerde bulunulmasını katkı sağlayacaktır.

\section{Kaynaklar}

Bryman, A., \& Cramer, D. (1990). Quantitative data analysis for social scientists, Routledge.

Brounen, D., Kok, N., \& Quigley, J. M. (2012). Residential energy use and conservation: Economics and demographics, European Economic Review, 56(5), 931-945. https://doi.org/10.1016/j.euroecorev.2012.02.007

Chang, T., Gupta, R., Inglesı-Lotz, R., Masabala, L.S., Simo-Kengne, B.D., Weideman, J.P. (2016). The causal relationship between natural gas consumption and economic growth: Evidence from the G7 countries", Applied Economics Letters, 23(1):38-46. https://doi.org/10.1080/13504851.2015.1047085

Coşkun, R., Altunışık, R., Bayraktaroğlu, S., ve Yıldırım, E., (2015). Sosyal bilimlerde araştırma yöntemleri, Sakarya Yayıncılık.

Çalmaşur, G. ve Çiğdem, T. (2020). Doğal gaz talep tahmini: Erzurum ili için bir uygulama, Ekonomik ve Sosyal Araştırmalar Dergisi, 16(1), 257-273.

Çokluk, Ö. (2010). Lojistik regresyon analizi: Kavram ve uygulama, Kuram ve Uygulamada Eğitim Bilimleri, 10(3), 1357-1407.

Fritzsche, D. J., (1981). An analysis of energy consumption patterns by stage of family life cycle, Journal of Marketing Research, 18(2), 227-232. https://doi.org/10.1177/002224378101800209

Gonzalez, A.D., Kanyama, A.C., Crivelli, E.S. \& Gortari, S. (2007). Residential energy use in one-family households with natural gas provision in a city of the Patagonian Andean Region, Energy Policy, 35(4), 2141- 2150. https://doi.org/10.1016/j.enpol.2006.07.004

Gujarati, N. D. (1999). Temel ekonometri, (3. Baskı), Literatür Yayıncılık, (Çevirenler: Ümit Şenesen \& Gülay Günlük Şenesen).

Gülcü, Y. ve Hatırlı, S. A.(2012). Doğalgaz kullanımını etkileyen sosyo-ekonomik faktörlerin analizi: Isparta ili örneği, Pamukkale Üniversitesi Sosyal Bilimler Enstitüsü Dergisi, 11, 83-95.

Hosmer D.W., \& Lemeshow, S. (2000). Applied logistic regression, Wiley. DOI: $10.1002 / 0471722146$.

Iş1k, C. (2010). Natural gas consumption and economic growth in Turkey: A bound test approach, Energy System, 1, 441-456. https://doi.org/10.1007/s12667-010-0018-1 
Kaynar, O., Taştan, S., \& Demirkoparan, F. (2011). Yapay sinir ağları ile doğalgaz tüketim tahmini, Atatürk Universitesi Iktisadi ve Idari Bilimler Dergisi, 10. Ekonometri ve İstatistik Sempozyumu Özel Sayıs1, 463-474.

Koyuncu, C., ve Bakırtaş, İ. (2005). Logit modeller yardımıyla sosyo-ekonomik ve demografik faktörlerin mevcut alternatif ısınma sistemleri üzerindeki etkileri (Kütahya Üzerine bir Uygulama), Atatürk Üniversitesi İktisadi ve İdari Bilimler Dergisi, 19(1), 37-54.

Lebe, F. ve Tatlı H. (2017). Türkiye'de doğalgaz tüketimi, sermaye ve istihdamın ekonomik büyümeyle ilişkisi: Eşbütünleşme ve nedensellik analizi, Dokuz Eylül Üniversitesi İktisadi İdari Bilimler Fakültesi Dergisi, 32(1), 1-28. https://doi.org/10.24988/deuiibf.2017321536

Liao, H. C. \& Chang, T. F. (2002). Space-heating and water-heating energy demands of the aged in the us, Energy Economics, 24(3), 267-284. https://doi.org/10.1016/S0140-9883(02)00014-2

Oktay, E., Naralan, A., ve Özçomak, M.S. (2008). Konutlardaki doğal gaz sisteminin tercih edilmesinde etkili olan faktörlerin araştırılması: Erzurum örneği, Atatürk Üniversitesi Sosyal Bilimler Enstitüsü Dergisi, 11(1), 341-353.

Özcan, K. M., Gülay, E., ve Üçdoğruk, Ş. (2013). Economic and demographic determinants of household energy use in Turkey. Energy Policy, 60, 550-557. http://dx.doi.org/10.1016/j.enpol.2013.05.046

Özçomak, M. S., Oktay, E. ve Özer, H. (2006). Erzurum ilinde potansiyel doğal gaz talebini etkileyen faktörlerin tespiti, EKEV Akademi Dergisi, 10(27), 309-321.

Özer, H. (2004). Nitel değişkenli ekonometrik modeller: Teori ve bir uygulama, Nobel Yayıncilık.

Pachauri, S. (2004). An analysis of cross-sectional variations in total household energy requirements in India using micro survey data, Energy Policy, 32(15), 1723-1735. https://doi.org/10.1016/S0301-4215(03)00162-9

Poortinga, W., Steg, L. \& Vlek C. (2004). Values, environmental concern, and environmental behavior: A study into household energy use, Environment and Behavior, 36(1), 70-93. https://doi.org/10.1177/0013916503251466

Sarak, H. \& Satman, A. (2003). The Degree-Day method to estimatethe residential heating natural gas consumption in Turkey: A case study, Energy, 28(9), 929-939. https://doi.org/10.1016/S0360-5442(03)00035-5

Selçuk, G. N. ve Pasinlioğlu, S. (2020). Türkiye'de hanehalkı ve konut büyüklüklerinin, doğalgaz tüketimi kapsamında değerlendirilmesi, Atatürk Üniversitesi Sosyal Bilimler Enstitüsü Dergisi, 24(4), 1861-1877.

Şenel, S., ve Alatlı, B. (2014). Lojistik regresyon analizinin kullanıldığı makaleler 
üzerine bir inceleme, Eğitimde ve Psikolojide Ölçme ve Değerlendirme Dergisi, 5(1), 35-52. https://doi.org/10.21031/epod.67169

Tarı, R. (2000). İzmit’te doğal gaz kullanımını etkileyen faktörler, Kocaeli Üniversitesi Sosyal Bilimler Enstitüsü Dergisi, 1, 69-76.

Tatlı, H. (2013). Konut sahipliğinin belirleyicileri: Hanehalkı reisleri üzerine bir uygulama, Akademik Yaklaşımlar Dergisi, 4(2), 40-63.

T.C. Enerji Piyasası Düzenleme Kurumu, Strateji Geliştirme Dairesi Başkanlığı, Doğal gaz piyasası, 2019 yılı sektör raporu, Ankara, 2020, 4 Mart 2021'de https://www.epdk.gov.tr/Detay/Icerik/3-0-94/dogal-gazyillik-sektor-raporu adresinden alındı.

Tuzun, H. ve Çayın, M. (2021). Doğal gaz enerjisi tercih nedenleri: Batman ili için bir saha çalışması, Dicle Üniversitesi Sosyal Bilimler Enstitüsü Dergisi, 26, 231-245.

Türkiye İstatistik Kurumu (TUIK), Nüfus göstergeleri, 8 Mart 2021'de https://data.tuik.gov.tr/Search/Search?text=nüfus adresinden alındı.

Türkiye Petrolleri A.O. 2019 Ham petrol ve doğal gaz sektör raporu, 2 Mart 2021'de https://www.tpao.gov.tr/file/2005/2019-tpao-sektor-raporu-3185ed3b4af5442c.pdf adresinden alındi.

Umutlu, H., ve Bayraç, H. N. (2020). Türkiye'de doğalgaz tüketimi ve ekonomik büyüme arasındaki ilişki: Granger nedensellik analizi, Sosyal Ekonomik Araştırmalar Dergisi, 20(40), 217-226. https://doi.org/10.30976/susead.738737

Verhallen, T.M.M. \& Raaij, V.W. F. (1981). Household behavior and the use of natural gas for home heating, Journal of Consumer Research, 8(3), 253-257. https://doi.org/10.1086/208862

Windmeijer, F. (1995). Goodness of fit measures in binary choice models, Econometric Reviews, 14(1), 101-116. https://doi.org/10.1080/07474939508800306 